\title{
Interview with Ludwig Reich
}

\author{
ARNOLD R. KRÄUTER
}

Abstract. On the occasion of his 80th birthday, Ludwig Reich, editor-in-chief of Aequationes Mathematicae from 1996 to 2008, gave an interview conducted via Zoom. This paper presents his answers to several questions regarding his education and academic life.

Mathematics Subject Classification. Primary 01A70, 01A65, 01A60, 01A61; Secondary 39B12, 39B32, 30B10, 30D05.

Keywords. Ludwig Reich, Biography, Iteration of power series, Functional equations, Differential equations in the complex domain, Algebraic geometry.

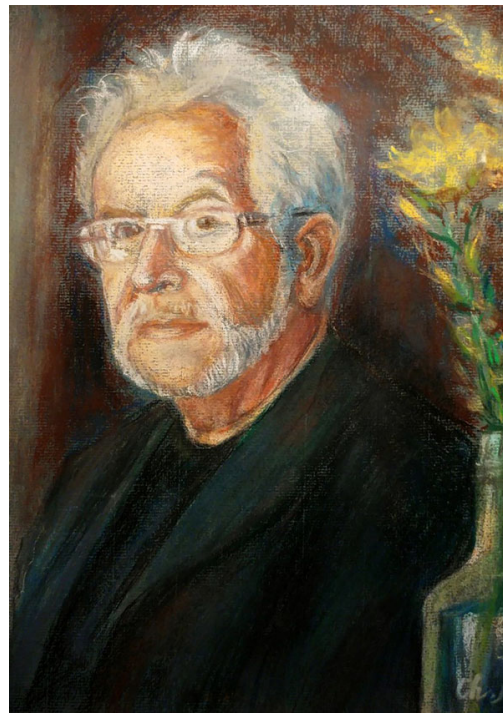

Ludwig Reich (Painting by Christa Reich)

Ludwig, when and how did you get interested in mathematics?

Actually, it happened already in the junior years of the grammar school. Among all subjects, mathematics definitely seemed to be the most interesting 
to me. Clearly, I got attracted to this topic by the school subject. What I found most fascinating (in the junior as well as the senior years) were intricate triangular constructions. I think that this topic is a perfect starting point to arouse interest and promote talent. Later on, I dealt with certain problems in descriptive geometry. Although I was not that brilliant at making geometric drawings, it just filled me with enthusiasm to arrive at the intellectual solution of such problems (e.g., finding the common perpendicular of skew lines) quite independently and without help. Moreover, inspired by Leonhard Euler's book Vollständige Anleitung zur Algebra, I studied algebraic equations of degrees three and four, respectively, and their solutions by radicals. Particularly, I tried to reduce this method for equations of degree four to those of degree three. In the course of my self study, I had encountered complex numbers, too. So I tried to establish a sort of divisibility theory in the ring of Gaussian numbers. These are just a few fascinating topics which I remember quite well. Finally, it was obvious to me that, if I were to study at university, mathematics would be my subject of choice.

One day when the teachers' library of our school was cleared out, I was lucky to pick the first volume of Heinrich Weber's Algebra. I tried to read and understand it, and found it quite stimulating. At that time (I was about 16 then), I was given a number of booklets published in the Göschen Series in Mathematics like Helmut Hasse's Höhere Algebra, Konrad Knopp's Funktionentheorie, and Arnold Scholz's Einführung in die Zahlentheorie. It was the volume by Hasse that I found most fascinating since I already had some knowledge about algebra. I admired it for its rigorous style which was quite different from that in Weber's book. Nevertheless, I preferred the latter, and this is still a part of my library. After all, I felt quite well prepared for university.

\section{After graduating from school you enrolled in the Philosophical Faculty of the University of Vienna, majoring in mathematics. When looking back, which of your academic teachers were most influential for you?}

Right at the beginning of my university studies, I encountered some teachers who impressed me quite a lot. One of them was Edmund Hlawka. In the first two semesters I had the opportunity to attend his course Differential and Integral Calculus that was accompanied by the corresponding exercises. Hlawka had a fast but fascinating way of lecturing. I clearly remember how he introduced real numbers by infinite decimal fractions. Due to time restrictions, he could not explain every detail of the construction but he provided clear hints to the crucial points. Later on, I also visited a number of other courses by Hlawka, e.g., Complex Functions. Another important person was Karl Prachar who was in charge of the Calculus Exercises and, eventually, would become my Ph.D. advisor. He held the title of an associate professor and offered, according to a teaching assignment, a series of interesting courses like Hilbert's Axiomatics 
of Plain Geometry and Introduction to Classical Algebraic Geometry, to name just two of them. The latter was based on the books Algebraische Geometrie by Bartel van der Waerden and Algebraic Curves by Robert Walker. Prachar's courses were very beneficial for me and, moreover, a good opportunity to get in personal touch with him.

Apart from these two remarkable personalities, I had a number of other academic teachers who, along with their courses, deserve to be mentioned, too: Nikolaus Hofreiter (Analytical Geometry, Number Theory, Algebra), Heinrich Brauner (Riemannian Geometry, Differential Geometry), Leopold Schmetterer (Functional Analysis), Wolfgang Schmidt (Diophantine Approximations), Paul Funk (Boundary Value Problems in Mathematical Physics), and Theodor Sexl (Theoretical Physics).

They all were impressive and influential individuals during my studies, and I owe them very much. Although they took a classical point of view, they provided substantial basics and ways of thinking which were invaluable to me.

\section{After finishing your Ph.D. in mathematics at the University of Vienna, it seemed quite obvious for you to continue working in that field. What were the stations in your academic career?}

As to my academic career, I have to return to the time when I was a student in Vienna. There I had the post of a so-called Wissenschaftliche Hilfskraft. As such I had to take care of the mathematics library jointly with my colleague Roman Schnabl (acquisition, inventory, and loans of books) and to supervise students in exercises. One day in 1962, Hlawka informed me about open positions for scientific assistants at the University of Bonn. I was invited to give a talk there, and shortly afterwards (in December 1962), I was assigned to such a position. After I had finished my Ph.D. in Vienna in 1963, I moved to Bonn. I was quite happy about that, since I met a creative atmosphere and got along perfectly with my new boss Ernst Peschl. Among other things, I was introduced to a variety of administrative tasks and I took care of a seminar for teaching candidates. Furthermore, I supervised the theses of candidates for the final state exam. Peschl supported me with respect to the habilitation and so, in 1967, I became a Dozent (i.e., lecturer) in mathematics.

One day, Hermann Schmidt from Würzburg visited Bonn and gave a talk in the mathematics colloquium, at the end of which I discussed some points with him. As a consequence, I was invited to give a talk at the University of Würzburg. There I was offered a new position, first as a substitute for a person on the leave, then as Wissenschaftlicher Rat and professor in mathematics. I accepted and, in 1969, I moved from Bonn to Würzburg. Though this university was a smaller one, I could work more independently and almost free of administrative burdens. Of course, my teaching duties were almost the same as before. 
Apparently due to recommendations by Peschl, I was invited to some appointment lectures soon. One of them took place at the University of Technology in Graz (where two former colleagues from Bonn, Karl Wilhelm Bauer and Wolfgang Hahn, were holding chairs in mathematics), and another one, surprisingly, at the University of Graz. In the end, I was offered a chair at the latter institution, and by October 1971 I was appointed full professor in mathematics there.

\section{What were your scientific interests at the beginning of your career?}

One day, Karl Prachar, whose acquaintance I had made in a number of discussions after his courses, offered to take me on as his doctoral student. In my Ph.D. thesis I was supposed to study generalizations of the following theorem by Martin Kneser: Let us be given finitely many curves in a projective space (e.g., a three-dimensional space over the complex numbers), and a non-empty finite set of points on these curves. Then, find a submanifold of codimension one that intersects the given curves exactly in those points. As it turned out very soon, I had to start tackling the problem by considering simple curves of genus zero. I also succeeded in proving analogous results for curves of orders three and four. Inspired by Prachar's courses, I independently tried to deal with some aspects of classical algebraic geometry. I knew that Francesco Severi and Eugenio Bertini had investigated rational systems of algebraic manifolds (e.g., curves) on another algebraic manifold (e.g., a surface) and established a number of so-called fundamental theorems about such systems. I attempted to re-write these theorems in the style of van der Waerden and to prove them. Due to an inspiring correspondence with the latter, I succeeded, and I was really proud of that. For several reasons I decided to stop working on problems in algebraic geometry, and instead to become familiar with Peschl's research area after my arrival in Bonn.

\section{For many years your favorite research topic was the analytic iteration in rings of (formal) power series. What was the source of your interest in that?}

In fact, this originated from my habilitation thesis which turned out to be enormously fruitful. Following a suggestion of Ernst Peschl, I studied canonical forms for contracting biholomorphic mappings in several complex variables in the neighborhood of a fixed point. I managed to establish the totality of these canonical forms. Moreover, I considered their application to the following interesting problem: Under what conditions is a biholomorphic mapping embeddable into a one-parameter group? (Note that the components of a 
contracting biholomorphic mapping are power series with analytic coefficient functions.) Subsequently, and jointly with Peschl, I turned my attention to the complete linearization of those mappings. It seemed to be obvious to drop the restrictions of convergence and contraction, and to study the embeddability problem also for formally biholomorphic mappings, in general, i.e., for automorphisms of the ring of formal power series in several variables. Based on my own preparatory results on complete linearization, I found answers to the general iteration problem in a series of papers I wrote jointly with Jens Schwaiger and other co-authors. A crucial point in finding suitable embeddability criteria was to emphasize algebraic aspects in rings of formal power series like the existence of iterative roots, commuting automorphisms, and (maximal) families of these. For a long time I had exclusively considered multidimensional iteration problems, until I discovered that the case of power series in one variable could deserve interest, too. In the corresponding investigations I was supported by Harald Fripertinger and Wojciech Jabłoński. Indeed, iteration theory has been one of my most important research areas.

\section{Naturally, when dealing with iteration theory, one encounters a} number of functional equations like the translation equation, the Schröder equation, and the Babbage equation. Thus, you also met many people with general interest in functional equations. Who stimulated you to study other types of functional equations, too?

Many stimulations came from János Aczél who visited us in Graz several times and also lectured on functional equations, in general, mainly treating classical problems. Among these were the functional equations for additive functions and generalized exponential functions. Although these are of importance in iteration theory, too, I started to consider them from a different point of view, focusing on their nature as solutions of functional equations in a joint paper with Jens Schwaiger. Other objects I studied were the Gołąb-Schinzel equation, derivations as special additive functions, and generalized Dhombres equations. The study of the latter was suggested to me by Jaroslav Smítal, and I was fortunate to contribute some aspects of complex analysis. Later on this work was continued with the support of Jörg Tomaschek.

\section{You can look back at a successful scientific career, and we know that your thirst for research still continues. Which of your research achievements do you appreciate most?}

That is not easy to answer! In the first place I would definitely mention the embeddability criteria for formally biholomorphic mappings into a one-parameter 
group. Originally, I dealt with this problem assuming the analyticity of the coefficient functions. A thorough study, however, revealed that embeddability is independent of any regularity conditions on the coefficients! I must admit that it took me quite a lot of effort to realize and prove this, and I am really proud of it. Moreover, I was able to characterize the existence of a maximal family of power series by a special type of differential equations, the so-called Aczél-Jabotinsky equation. This was, actually, a very surprising connection!

\section{Which mathematicians had a substantial effect on your own research activities and which of your scientific cooperations did you cherish most?}

Let me begin with the people from places other than Graz. I appreciated very much the opportunities to work with Ernst Peschl, Jaroslav Smítal, Wojciech Jabłoński, and Walter Benz. Each of them had a special personal working style, and I felt enriched in several respects when doing interesting and fruitful research with them.

Then I feel very indebted to the members of my chair and colleagues in Graz: Detlef Gronau, Jens Schwaiger, Harald Fripertinger, and Franz HalterKoch. This also applies to many of my former Ph.D. students. I deeply appreciate their partnership in many research projects.

I was not only influenced by people doing joint research with me, but also by personal contacts and discussions. That includes those of my academic teachers Edmund Hlawka and Karl Prachar, and, later on, János Aczél and György Targonski. The latter was a particularly shining example for me, and I could benefit a lot from his stimulating ideas and precisely stated problems.

Other suggestions came from the reading of scientific literature and the correspondence with outstanding scientists. I remember my helpful exchange with van der Waerden when I was working in algebraic geometry. I found it rewarding and inspiring to read Carl Ludwig Siegel's lectures for my investigations on canonical forms for systems of differential equations as well as biholomorphic mappings.

\section{Owing to your international connections in the scientific community you spent a number of research stays. Which of these visits were most memorable for you?}

When I was in Bonn, I spent the summer semester 1969 at the Free University in Berlin as a visiting professor. Then I made several visits to Waterloo (Ontario, Canada), starting with the winter semester 1975/76 and followed by two shorter stays. I enjoyed them very much since I had plenty of time for research 
purposes. Moreover, I was invited for two months each by the universities of Rostock and Hamburg, in the latter case supported by the Wilhelm Blaschke Foundation. Quite frequently, however, I visited one and the same university several times but for shorter periods (one week or so), e.g., Opava in Czechia and Katowice in Poland.

\section{For ten years you have now been professor emeritus in mathematics. How do you spend your time in your retirement, and what are your future plans?}

There was a substantial change in my daily routines once I had retired. Needless to say, my life then focused on my wife and my family. I also spent a lot of time with my grandchildren after we had moved from Graz to my hometown Mödling (near Vienna). I started to do daily walks regularly and smaller hiking tours occasionally. I like playing the piano and listening to music. Naturally, one also has to concentrate on coping with everyday life, which is becoming more arduous and complicated. Of course, I still have a lot of plans, also mathematically. It is quite undecided, however, which of them I will be able to realize. A number of manuscripts are waiting to be finished, but I do not know whether I will accomplish that. Surely, I will be happy to give talks about new findings from time to time in the seminar founded by me.

\section{Teaching was a substantial part of your work at university. What impressions do you remember concerning your teaching for freshmen as well as graduate students?}

I definitely liked to give courses, and I devoted quite a lot of time to them. This applies to both their presentation in the lecture hall and their preparation in the office or at home. At the beginning of their careers many people believe that the majority of the time they spend on preparing courses can be devoted to special courses from which they can learn a lot of new things. Reality, however, looks quite different! It is the presentation of main courses for a large audience that deserves more attention. Personally, I made the experience that I could also learn very much when preparing courses on elementary or classical topics. After all, I think that I really enjoyed teaching, not only in courses but also in seminars. Somehow, I missed teaching in the first months of my retirement. However, soon I got used to the new situation.

I had started giving lectures even before getting my habilitation. When I was a student in Vienna, I once filled in for Leopold Schmetterer in his course Calculus II for six hours. I remember that I had to talk about the proof of the implicit function theorem based on barely readable handwritten 
notes of the professor. In Bonn I often had to fill in for Ernst Peschl when he attended academy meetings. This was a good experience for me, I learned a lot, and so I familiarized myself with teaching. Also in Bonn, I was once facing an unpleasant situation at the beginning of the course Mathematics for Economists. Although I was well-prepared and it did not require more than school mathematics, the students had a lot of difficulties following me. That left me quite desperate, too. Fortunately, however, the situation relaxed after two or three months and everybody (me included) was satisfied. In Würzburg and Graz I could teach independently due to my position.

Many participants of your courses were fascinated by the fact that you lectured without any written notes. What made you decide to give the presentations entirely by heart?

When I was in Bonn I got to know a couple of academic teachers who lectured freely and never used a manuscript, e.g., Ernst Peschl, Wolfgang Krull, and Friedrich Hirzebruch. Ambitious as I was, I tried to emulate them. For sure, it takes some time to memorize the contents of a course unit but the presentation will be a much livelier one. After having lectured a course twice or more often I got used to doing it by heart.

\section{From the late 1960s on you had more than 20 doctoral students. Do you have a guess why you were such a popular Ph.D. advisor?}

Well, this is a double edged thing! You might be a popular advisor because you pose a topic that is very easy to deal with or can (at least partly) be copied from the internet. That is one way to popularity. Of course, the other possibility is to suggest a topic that is well-known to you and close to your own current or former research areas, where good estimations of the outcome can be made in advance. Another important ingredient is that you take your time for counseling and guiding the candidates personally and as frequently as possible. That is what I did, and I enjoyed doing it this way!

\section{What would you recommend to young people who want to study mathematics?}

If a young man or woman shows interest in studying mathematics, I would tell him or her that, to some extent, there are a couple of indispensable prerequisites. These are: diligence, endurance, a good memory, and interest in mathematical problems per se aroused already in school. Moreover, one needs 
abstract thinking skills and intuition. Otherwise one would not be able to have creative ideas or to prove issues. In mathematics you need both to pose problems and to solve them. These are inseparable skills! Perhaps it is exactly this point which explains why sometimes there are many students in mathematics but only a few really good ones. Freshmen should be told that the requirements for successful and satisfying studies in mathematics (also for prospective teachers) are high.

\section{Thank you very much, Ludwig, for this extensive interview and best wishes for the future!}

Remark. Additional biographical references about Ludwig Reich can be found in [1].

\section{Acknowledgements}

The interviewer's sincere gratitude goes to Harald Fripertinger for creating the technical requirements for the interview, Jens Schwaiger for numerous helpful hints and diverse support, and to Thomas Schwaiger for his invaluable assistance in improving the readability of the text. Finally, my thanks go to the anonymous referee for her/his useful comments.

Funding Open access funding provided by Montanuniversität Leoben.

Open Access. This article is licensed under a Creative Commons Attribution 4.0 International License, which permits use, sharing, adaptation, distribution and reproduction in any medium or format, as long as you give appropriate credit to the original author(s) and the source, provide a link to the Creative Commons licence, and indicate if changes were made. The images or other third party material in this article are included in the article's Creative Commons licence, unless indicated otherwise in a credit line to the material. If material is not included in the article's Creative Commons licence and your intended use is not permitted by statutory regulation or exceeds the permitted use, you will need to obtain permission directly from the copyright holder. To view a copy of this licence, visit http:// creativecommons.org/licenses/by/4.0/.

Publisher's Note Springer Nature remains neutral with regard to jurisdictional claims in published maps and institutional affiliations.

\section{Reference}

[1] Kräuter, A.R.: Ludwig Reich zum 70. Geburtstag. Eine Würdigung. In: Ludwig Reich zum 70. Geburtstag. Festkolloquium, Graz, 29. Jänner 2010, Harald Fripertinger, Wolfgang Prager, and Jens Schwaiger (eds.) Grazer Mathematische Berichte, vol. 359, pp. 1-24 (2011) 
Arnold R. Kräuter

Chair of Mathematics and Statistics

Montanuniversität Leoben

Leoben 8700

Austria

e-mail: arnold.kraeuter@gmx.at

Received: September 30, 2021

Accepted: October 19, 2021 